\title{
Demyelination in canine distemper encephalomyelitis: an ultrastructural analysis
}

\author{
BRIAN A. SUMMERS ${ }^{1}$ and MAX J. G. APPEL ${ }^{2}$ \\ Departments of ${ }^{1}$ Pathology and ${ }^{2}$ Microbiology (James A. Baker Institute), New York State College of Veterinary Medicine, Cornell \\ University, Ithaca, NY 14853, USA
}

Received 29 April 1987; revised 17 July 1987; accepted 27 July 1987

\begin{abstract}
Summary
A morphological study of selected white matter lesions was carried out in three dogs with canine distemper encephalomyelitis. Two dogs had experimental infections while the third was a spontaneous case. Two stages were identified in the process of demyelination. The earliest evidence of myelin injury was a ballooning change in myelin sheaths involving single or multiple axons. This was followed by a progressive stripping of compact sheaths by the cytoplasmic fingers of phagocytic cells which infiltrated and removed myelin lamellae. Some axonal necrosis also accompanied these changes. Where demyelination occurred, canine distemper viral nucleocapsids were found in astrocytes, macrophages, ependymal cells and infiltrating lymphocytes. In contrast, oligodendrocytes were conspicuous by their apparent lack of infection. Thus it seems that myelin loss cannot be ascribed to oligodendrocyte infection. Perturbed astrocyte function following canine distemper viral infection may cause oedema of myelin sheaths, leading to ballooning and primary demyelination. Cells which phagocytosed myelin were mainly identified as microglial cells with lesser involvement by astrocytes. Rarely, oligodendrocytes also acted as macrophages. Myelin debris was engulfed in bulk or as small droplets into coated pits. Remyelination was present in established plaques although not in great abundance, perhaps due to the diminished oligodendrocyte numbers and a relative increase in immature forms of these cells. These observations are compared to similar changes observed in other demyelinating diseases of animals and man.
\end{abstract}

\section{Introduction}

Of the human demyelinating diseases, multiple sclerosis (MS) remains the most important with perhaps 250000 cases in the United States alone (Waksman, 1981). The aetiology and pathogenesis of this disorder remain elusive but are areas of active investigation. Studies of murine models of MS have demonstrated that myelin loss may follow lytic oligodendrocyte infection (mouse corona virus infection, see Lampert et al., 1973) or can result from an immunopathological attack on persistently infected oligodendrocytes (Theilers disease, see Rodriguez et al., 1983). Canine distemper encephalomyelitis (CDE) has been proposed as a further model of MS (Koestner, 1975). Canine distemper is caused by a morbillivirus, certain strains of which will induce a high incidence of CNS demyelination (Summers et al., 1979; Higgins et al., 1982b).

Although several authors have reported on the ultrastructural changes in spontaneous (Wisniewski et al., 1972; Raine, 1976) and experimental (McCúllough et al., 1974; Higgins et al., 1982b) CDE, the mechanism of demyelination remains unclear. Previous studies have documented the areas of predelic- tion within the CNS for demyelinating lesions to develop, and their chronological appearance (McCullough et al., 1974; Summers et al., 1979). Given this background information, we have performed a detailed electron microscopic study of selected areas of the neuraxis in an attempt to clarify the pathogenesis of demyelination in this viral encephalomyelitis of the dog.

\section{Materials and methods}

The CNS tissues studied were derived from three dogs two experimental and one spontaneous case of CDE. The former resulted from intranasal infection of specificpathogen-free Beagle dogs with the Cornell A75-17 strain of canine distemper virus (CDV). These dogs were perfused at 24 and 45 days post-infection with $3-4$ litres of $1 \%$ Karnovsky's solution delivered into the left ventricle. Specimens were taken from periventricular white matter areas: the crus of the fornix at the lateral ventricle and the cerebellar medulla adjacent to the fourth ventricle. The third animal (spontaneous case) had shown neurological signs for 4 weeks. Following perfusion of this animal, tissue was taken from the ventral funiculus of the lumbar spinal 
cord. Tissue from this dog was kindly provided by Dr C. S. Raine, New York. From the experimental cases, adjacent areas of the brain were postfixed in $10 \%$ buffered formalin and processed through paraffin for light microscopy. Sections were stained with haematoxylin and eosin. Tissues for electron microscopy were routinely postfixed in $1 \% \mathrm{OsO}_{4}$, dehydrated and embedded in Epon. Sections, $1 \mu \mathrm{m}$ thick, stained with toluidine blue were examined for white matter lesions. Selected areas were thin sectioned, stained with uranyl acetate and lead citrate and examined in a Philips 300 electron microscope.

\section{Results}

\section{Light microscopy}

In paraffin sections from the dog killed at 24 days post-infection, myelin injury was first seen as areas of sponginess or vacuolation, often below the ependyma or pia mater. As this spongiform change became more severe, vacuoles apparently coalesced, producing a zone (or plaque) of demyelination (Fig. 1). Very rarely it was possible to visualize the axon within the distended myelin sheaths (Fig. 2). This myelin change was consistently accompanied by a pronounced astrocytosis; some reactive astrocytes had hypertrophic, open-faced nuclei and swollen cytoplasm (Fig. 3). Multi-nucleated astrocytes were also seen. A mild proliferation of rod cells (microglia) accompanied this astrocytosis. Expansion of white matter lesions appeared to develop by further ballooning change at the margin of a zone of demyelinated white matter (see Fig. 1); a few distinct vacuoles could usually be found within the demyelinated zone as well. As lesions developed an inflammatory nature (seen at day 42 and in the spontaneous case) with an influx of lymphocytes and plasma cells, the demyelinated neuropil became more rarified, disrupted and in areas frankly necrotic if the mononuclear cell infiltrate was heavy. Foamy macrophages were evident in the meshwork of naked axons and glial processes.

In plastic sections, $1 \mu \mathrm{m}$ thick, greater detail of the ballooning myelin change could be appreciated. Furthermore, individual demyelinated axons could be confidently identified (Fig. 4). Initially the Vir-
chow-Robin spaces were empty, apart from rare flattened perivascular cells, best appreciated in plastic sections. As the lesions become inflammatory it was evident that the perivascular cuffs were often located at the margins of the plaques (Fig. 5) and not necessarily related to plaque expansion.

\section{Electron microscopy}

In areas of otherwise normal white matter, severely ballooned myelin sheaths, derived from a single axon, could be found (Fig. 6). The affected axon sometimes had a misshapen or distorted profile, as if compressed, but filament accumulation within the fibre was usually lacking. The ballooned myelin sheath was formed from full or partial thickness of the sheath. It was not possible to determine whether sheaths split consistently at the major dense line or intraperiod line. Ballooned sheaths were empty or contained a slightly flocculent, electron-dense material. Sometimes processes of astroglial or microglial cells were seen adjacent to the swollen sheath. (Because of the controversy regarding microglial cells - see Kitamura et al. (1984) and Schelper \& Adrian (1986) - which is discussed below, we have used this term to denote the precursors of the predominant macrophages within the plaques.) In other areas, myelin sheath ballooning was seen about groups of several axons. Whereas some fibres appeared intact, others were swollen with the accumulation of lysosomal and membranous dense bodies, mitochondria and multivesicular bodies. These degenerate, sometimes swollen axons were also partially or totally denuded of myelin (Fig. 7). Axonal necrosis and lysis was evident from large, empty myelin sheaths and from broad expanses of astroglial and microglial cell processes, apparently filling the neuropil where destruction of myelinated fibres had occurred.

Neighbouring these areas of ballooning myelin change were foci of primary demyelination. Such areas contained virus-infected cells of several types. Canine distemper viral nucleocapsids were observed within macrophages and ependymal cells (Fig. 8) and within astrocytes and infiltrating lymphocytes. Infection of all these cells has been well documented in

Fig. 1. Cerebellum showing pale, mildly gliotic demyelinated plaque $(\mathrm{P})$, myelin vacuolation at the margins and normal white matter. H. and E. $\times 150$.

Fig. 2. Axons (arrows) can be seen traversing ballooned myelin sheaths. $H$. and $\mathrm{E} . \times 480$.

Fig. 3. Hypertrophic astrocytes (arrows) in white matter adjacent to granule cells of cerebellar cortex. $\mathrm{H}$. and $\mathrm{E}$. $\times 480$.

Fig. 4. Early white matter lesion adjacent to ependymal cells (E). Note prominent myelin vesiculation. One axon shows segmental demyelination with ballooning of the adjacent internode (single arrow). Another axon is fully demyelinated (double arrows). Plastic section, $1 \mu \mathrm{m}$ thick. $\times 480$.

Fig. 5. Inflammatory white matter lesion. A perivascular cuff (blood vessel V) is seen at the edge of a plaque. The lesion contains a few ballooned sheaths (b), several demyelinated axons (arrows) and a light diffuse infiltrate of mononuclear inflammatory cells $(\mathrm{M})$. Plastic section, $1 \mu \mathrm{m}$ thick. $\times 1280$. 

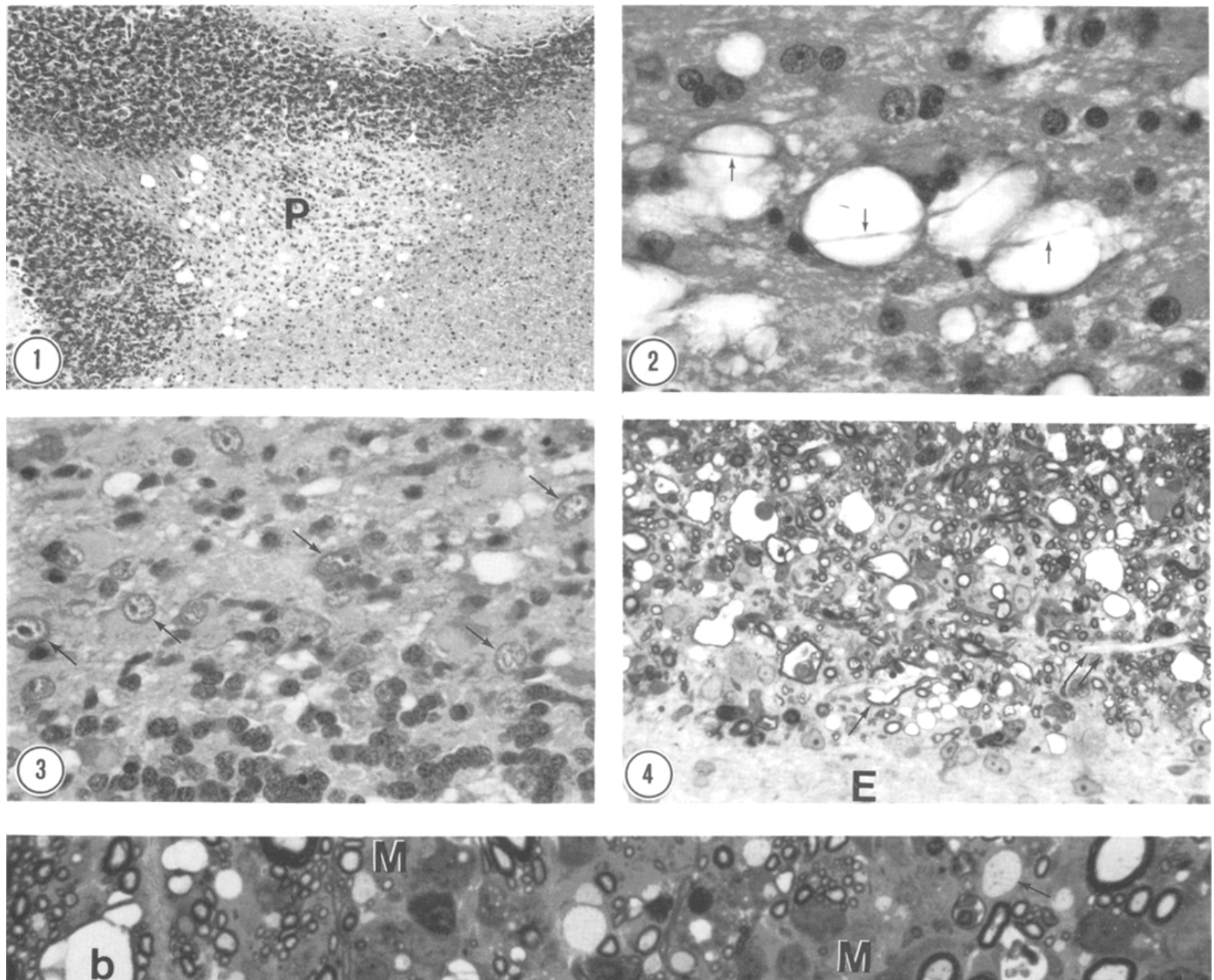

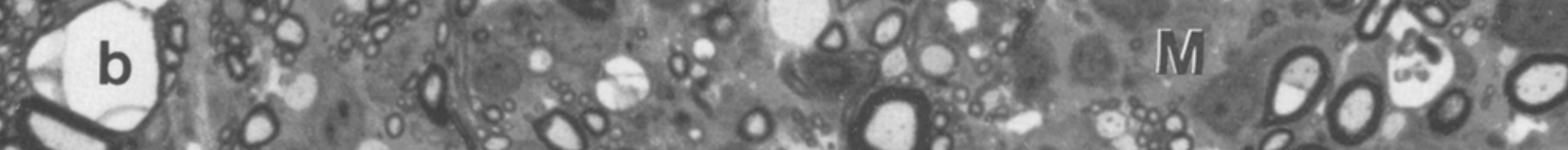
$8200 \% \div 2 \div 2 \times 0$

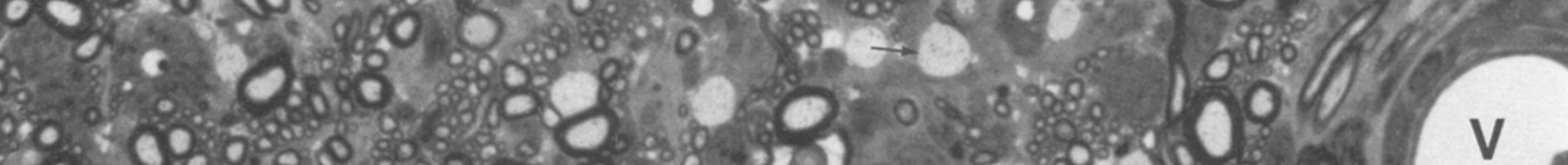

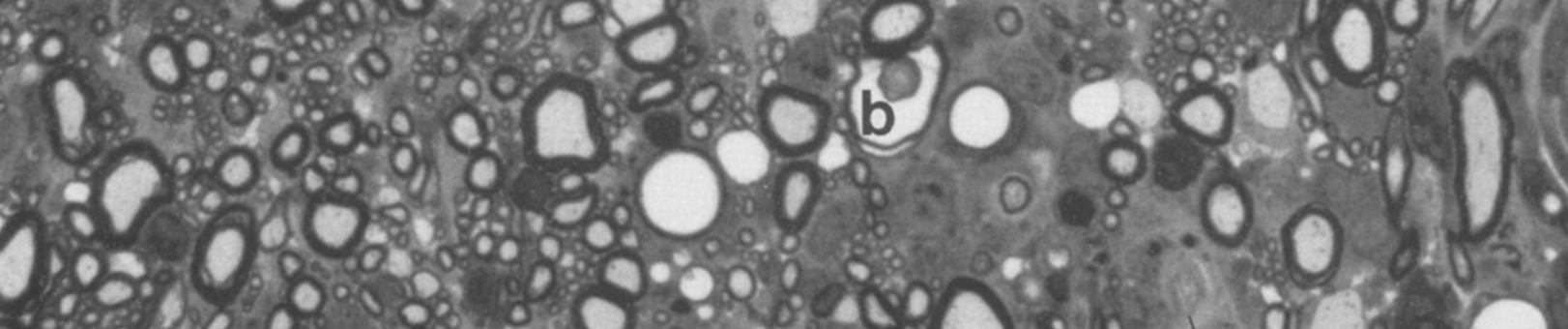

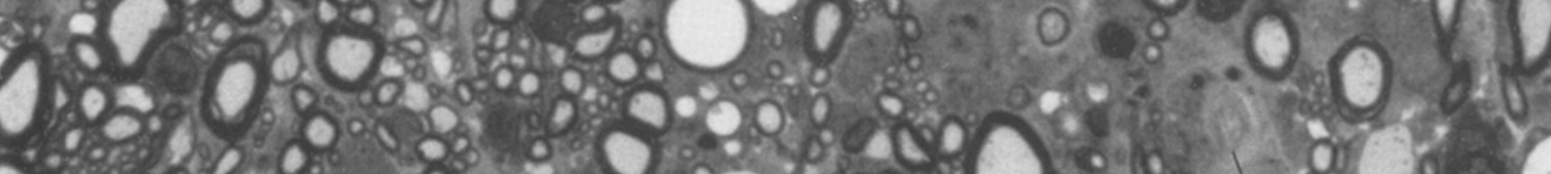

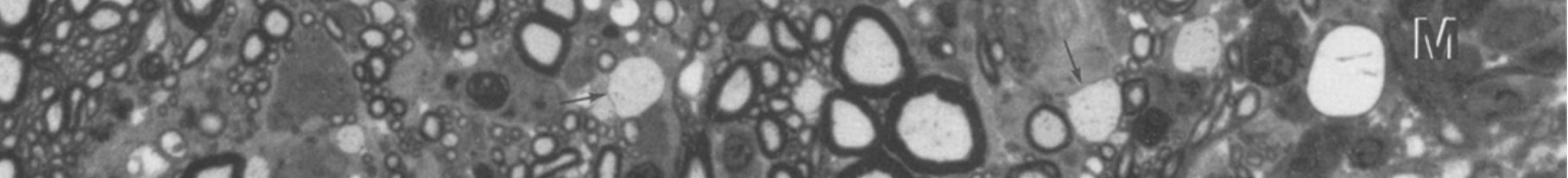

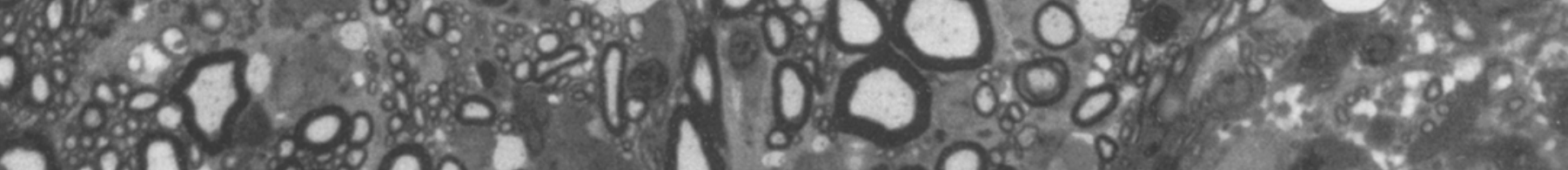
0.00900 i 900 . $x$ (0) 0 . $030 \%$ 
previous studies (Wisniewski et al., 1972; McCullough et al., 1974; Summers et al., 1978, 1979, 1984; Higgins et al., 1982b). In contrast, however, viral nucleocapsids were conspicuously lacking in oligodendrocytes, being seen in but a single light oligodendrocyte.

Areas of demyelination contained increased numbers of astrocytes and microglial cells. Reactive fibrous astrocytes (Fig. 9) were identified by their ovoid nuclei with dispersed chromatin, pale cytoplasm and conspicuous bundles of intermediate filaments. Hypertrophic astrocytes were cells with more extensive cytoplasm which contained many microtubules but few filaments, several lysosomes and free ribosomes in the perikaryon. Some hypertrophic astrocytes had phagocytosed loops of myelin (Fig. 10) or contained digestion products thereof.

In contrast to astrocytes, microglial cells were more electron-dense with clumped heterochromatin, a more granular cytosol and characteristic long profiles of rough endoplasmic reticulum (Fig. 11). Tubuloreticular inclusions (see Fig. 6), which characteristically appear within the rough endoplasmic reticulum in CDE and other diseases (Grimley \& Schaff, 1976) were a very useful marker for microglial cells; they were also observed in endothelia and pericytes.

Loss of compact myelin apparently began by the spiral wrapping of cytoplasmic processes of macrophages around intact fibres. These processes then penetrated the sheath, resulting in a concentric stripping of myelin lamellae away from the axon. Such processes could be observed within the sheath (Fig. 12) and very rarely the complete histiocyte came to occupy an adaxonal position. Stripping only occurred of compact myelin and was never seen where myelin ballooning had occurred. Separated myelin fragments were found as free, extracellular droplets or within the cytoplasm of the myelin stripping cells - which most often had the features of microglia. Occasionally, small myelin fragments were observed within coated pits (Fig. 12) on the surface of macrophages. It was very common to observe individual, fully demyelinated axons adjacent to a group of normal (myelinated) fibres. On rare occasions where nerve fibres were sectioned in longitudinal profile, segmental demyelination was observed.

Axons which had been demyelinated were often enclosed by the broad expanse of macrophage processes (Fig. 13). It appeared that these processes then retracted, leaving naked axons which floated free in the neuropil or were loosely ensheathed by the processes of fibrous astrocytes (Fig. 14).

Three types of cells were involved in myelin phagocytosis. Most were microglia (Figs 11-13) which most often appeared to perform the myelin stripping; less frequently, astrocytes contained myelin fragments. On very rare occasions, myelin loops were found within the cytoplasm of oligodendrocytes (Fig. 15).

As plaques of demyelination expanded, numbers of oligodendrocytes within the demyelinated zone were reduced compared to areas of adjoining white matter. Rare necrotic cells were seen within the plaque, but could not specifically be identified. Oligodendrocytes could readily be found at the plaque margin and were conspicuous by the frequent presence of centrioles, perhaps indicative of mitotic. activity (Raine et al., 1981). Centrioles, however, were observed in other cells, albeit less frequently (mostly macrophages). In well-developed lesions, many remaining oligodendrocytes were of the light variety (Mori \& Leblond, 1970). In contrast, medium and dark oligodendrocytes predominated in white matter with early lesions and in normal white matter.

The process of demyelination in CDE evolves from a non-inflammatory to an inflammatory state (McCullough et al., 1974; Summers ef al., 1979). Tissue examined from the dog studied 24 days post-infection generally lacked perivascular mononuclear inflammatory cells. Occasional reactive macrophage-like cells, possibly derived from vascular pericytes, were found about some capillaries (Fig. 16); some of these cells contained tubuloreticular inclusions. In the 42-day dog and the spontaneous case, monocytes, lymphocytes and plasma cells from the perivascular compartment percolated into the lesion areas (Fig. 17), but were not clearly associated with expansion of the zone of demyelination (see Fig. 5).

Remyelination was only a sporadic observation and was identified as inappropriately thin sheaths unattended by myelin stripping or the presence of myelin phagocytosis. Rare findings were aberrantly located paranodal loops and tapering of the myelin sheath.

\section{Discussion}

In this study of demyelination in CDE we have focused on limited areas of the neuraxis which were defined, in previous investigations (McCullough et al., 1974; Summers et al., 1979), as harbouring injured myelin consistently. Light microscopic examination showed that ballooning was the earliest evidence of myelin disruption. As the plaques expanded it was possible to identify a centrally demyelinated core, a narrow vacuolated zone at the margin and the adjacent normal white matter. At the electron microscopic level, this sponginess was found to result from pronounced ballooning of myelin sheaths from the axon. Sometimes the balloon myelin resulted from a split in the myelin sheath, leaving part of the sheath still covering the axon while the remainder formed the balloon. Myelin preservation was inadequate to determine whether sheaths split at the 

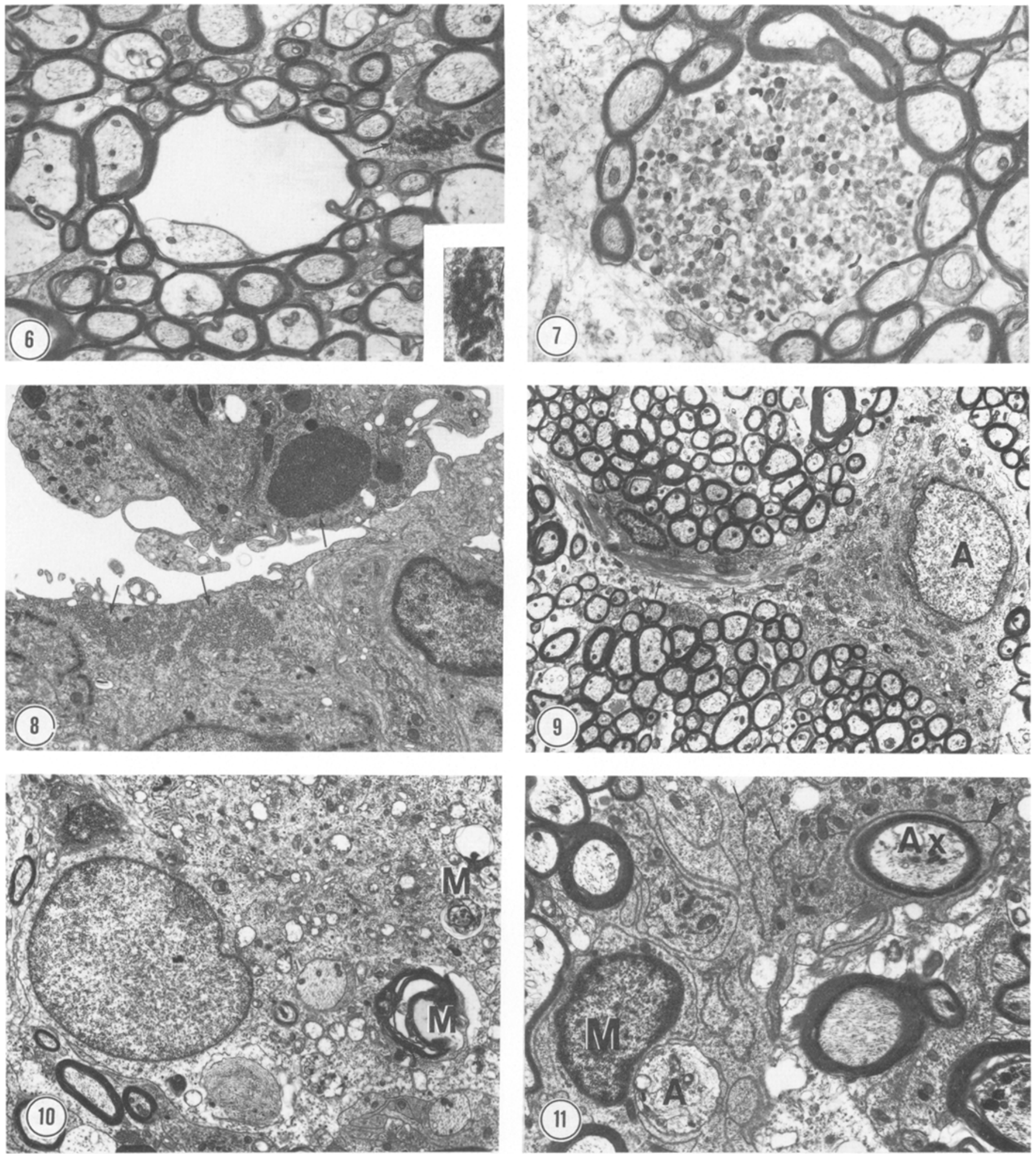

Fig. 6. Ballooning of myelin from a single axon. Other myelinated fibres are intact. Microglial cell process, containing a dense tubuloreticular inclusion (arrow), abuts the ballooned sheath. $\times 6300$. Inset shows the tubuloreticular inclusion contiguous with the endoplasmic reticulum (arrow). $\times 8820$.

Fig. 7. A severely swollen, demyelinated spheroid sits among other intact myelinated fibres. $\times 9300$.

Fig. 8. At the surface of the fourth ventricle a macrophage and an ependymal cell contain canine distemper viral nucleocapsids (arrows). $\times 6300$

Fig. 9. Reactive astrocyte (A) extends filament-bearing processes (arrows) among fascicles of myelinated axons. $\times 3100$.

Fig. 10. Phagocytic, hypertrophic astrocyte contains myelin debris $(\mathrm{M}) . \times 5100$.

Fig. 11. Nucleus of a microglial cell (M) with clumped heterochromatin; cytoplasmic profiles contain characteristic long profiles of rough endoplasmic reticulum (arrows). Notice one naked axon $(A)$ and another $(A x)$ from which myelin is being stripped (arrowhead). $\times 6300$. 

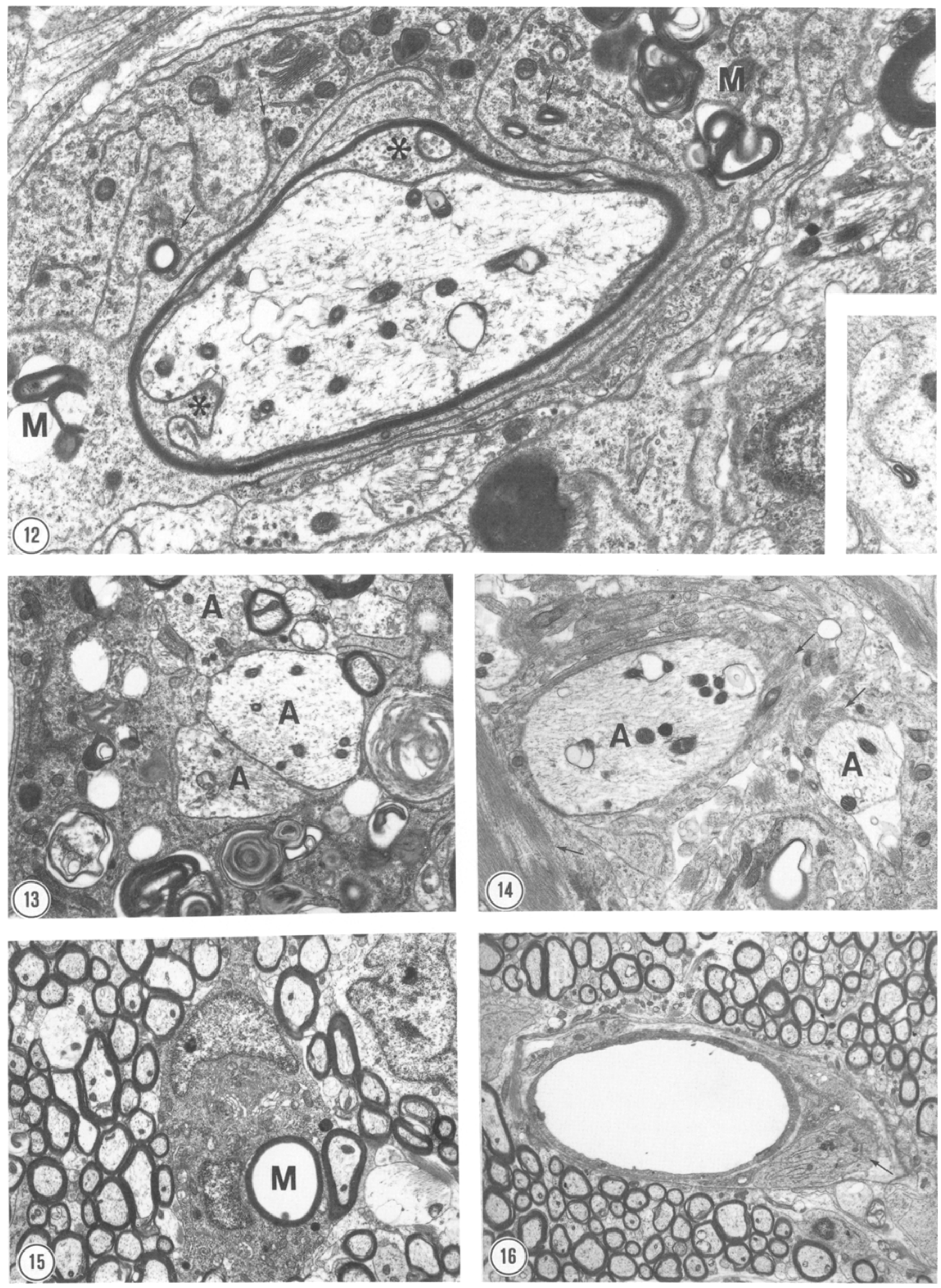


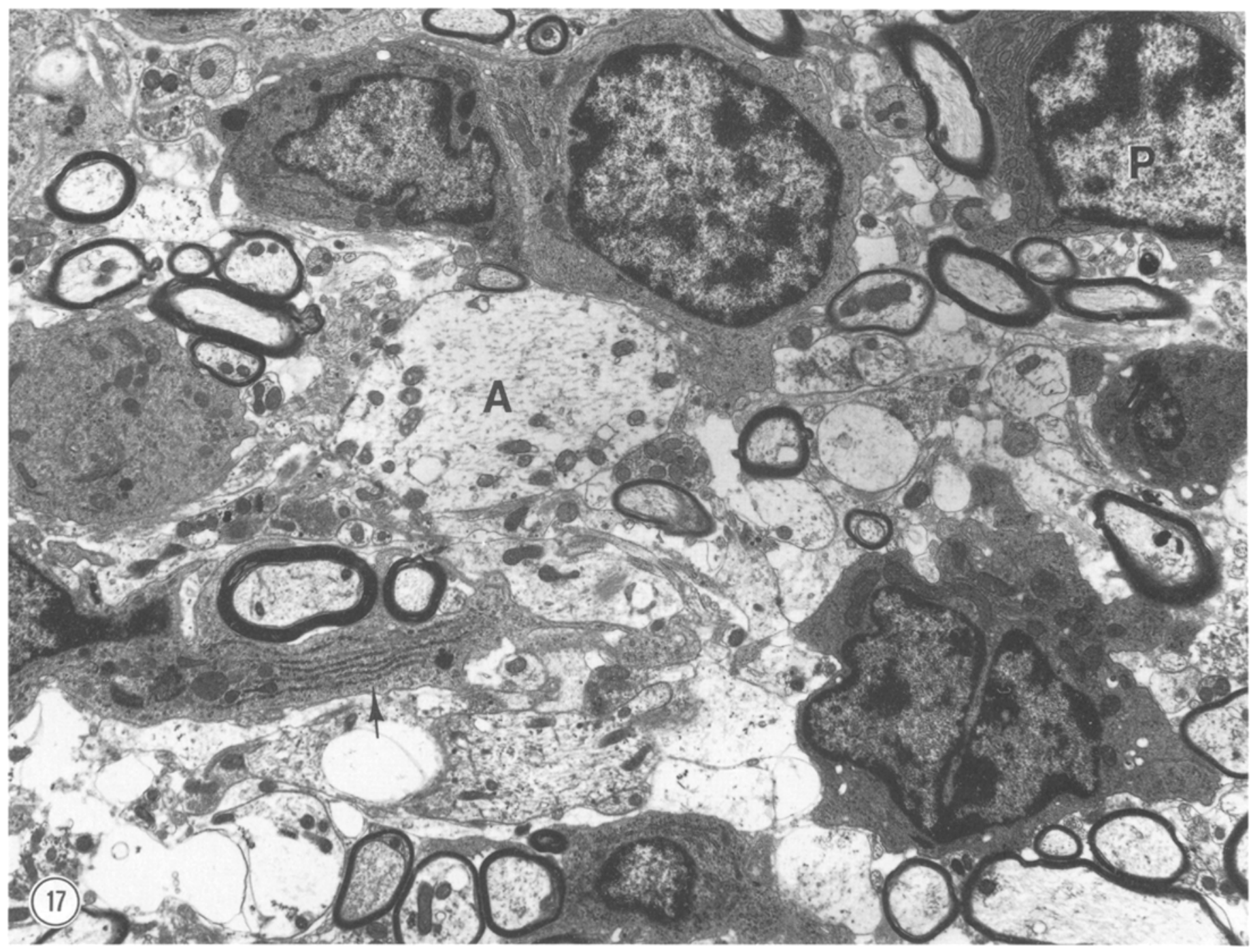

Fig. 17. A variety of mononuclear cells (plasma cell $P$ ) infiltrate a plaque. Notice the process of a macrophage with characteristic long profiles of rough endoplasmic reticulum (arrow). Although the plaque contains a demyelinated axon (A), many fibres are still ensheathed. Some with thin sheaths may be in the process of remyelination. $\times 7100$.

major dense line or intraperiod line. However, Higgins et al. (1982a) identified the intraperiod line as this site. This ballooning change may reflect intramyelinic oedema and is very similar to that seen in certain toxicities, such as triethyl tin, cuprizone and ethidium bromide, in which conditions the split occurs at the intraperiod line (Aleu et al., 1963; Ludwin, 1978; Yajima \& Suzuki, 1979). In general the ballooned sheaths were empty, but occasionally contained a flocculent material, perhaps proteinaceous oedema fluid. Furthermore, it was quite common to find that the axon, about which the

Fig. 12. Active demyelination of an axon by cytoplasmic processes of a macrophage which contains abundant myelin debris (M). Note that macrophage processes have extended inside the sheath (asterisks) and have focally distorted the axon. Occasional coated pits are seen (arrows). $\times 18400$. Insert shows a myelin droplet within a coated pit. $\times 26000$.

Fig. 13. Three demyelinated axons (A) are enclosed by the processes of a typical macrophage (microglial cell) which contains myelin and myelin breakdown products. $\times 9300$.

Fig. 14. Two naked axons (A) are encircled by astrocyte processes. Bundles of intermediate filaments are numerous (arrows). $\times 9300$.

Fig. 15. A dark oligodendrocyte contains a large loop of myelin (M). Astrocyte cell body and processes to the right. $\times 5100$.

Fig. 16. In an area of intact white matter, profiles of a cell are seen in the perivascular compartment (arrow. $\times 3500$. 
ballooning had occurred, was distorted; compression by oedema fluid within the ballooned sheath may be the explanation.

Spongiform white matter change has long been recognized from light microscopic studies of $\mathrm{CDE}$ (Campbell, 1957; Innes \& Saunders, 1962), but as yet has not been put into the context of the developing lesion. Similar spongiform change has been described in association with other demyelinating diseases including Semliki Forest virus and mouse hepatitis virus infections of mice (Sheahan et al., 1983; Lavi et al., 1984), herpes simplex virus infection of rabbits (Kristensson \& Wisniewski, 1978) and some forms of experimental allergic encephalomyelitis (EAE) in rats (Lassmann et al., 1980). In some areas, myelin sheath ballooning was associated with more degenerative changes and axonal spheroid formation. Spheroids were also often partially or totally denuded. Higgins et al. (1982a) have referred to this process of concurrent axonal and myelin damage in $\mathrm{CDE}$ as 'complex necrosis'.

The early spongiform change is accompanied and perhaps preceded by a local proliferation of astroglial and microglial cells (Summers et al., 1979; Vandevelde et al., 1982, 1983; Higgins et al., 1982b). Although the ultrastructural features of the microglial cell are well documented (Mori \& Leblond, 1969), its source and ultimate function are still strongly debated (Schelper \& Adrian, 1986). The mesodermal derivation of microglia is now less secure (Kitamura et al., 1984). Central to the issue is whether all CNS macrophages are of monocyte origin or whether these microglial cells are indeed a local source of phagocytes. From this study it appeared that cells compatible with reactive microglia, their processes often conveniently identified ultrastructurally by tubuloreticular inclusions within their endoplasmic reticulum, most commonly performed the process of myelin stripping and phagocytosis. This occurred in the absence of flagrant perivascular cuffs of mononuclear cells (such as monocytes). However, in evaluating blood vessels for such cells we sometimes noted swollen pericytic cells or extravascular, flattened macrophage-like cells in the perivascular compartment; pericytes may contribute to the pool of local macrophages (Baron \& Gallego, 1972) and have been designated by others the 'pericytic microglia'.

A second glial cell which reacts early in these lesions is the astrocyte. We found that the hypertrophic (protoplasmic?) form of these cells revealed a phagocytic potential, an observation made previously in this disease by Raine (1976) and Higgins et al. (1982b) and in other circumstances, both in vivo (Ludwin, 1978) and in vitro (Kusaka et al., 1985, 1986). Although astrocytes are conventionally thought of as glial cells involved in the repair process, we have previously suggested that their proliferation pre- ceded myelin loss in CDE (Summers et al., 1979). Indeed this observation is central to the argument that these cells are fundamentally involved in the process of demyelination in this canine disease. A proliferation of astroglial cells could follow direct virus infection of these cells. However, a diffuse astrocytosis also occurs early in non-infectious demyelinating diseases, such as EAE (Smith et al., 1983), perhaps as a consequence of widespread tissue oedema.

The pathogenesis of demyelination in CDE is still unclear. Compelling evidence from ultrastructural studies of CDV-induced oligodendrocyte necrosis is lacking. Indeed electron microscopic demonstration of oligodendrocyte infection was not offered by Wisniewski et al. (1972), McCullough et al. (1974), Summers et al. (1979, 1984) or Higgins et al. (1982b). Raine (1976) described viral inclusions in 'occasional oligodendrocytes'. Occasional degenerating or necrotic cells were found in the white matter lesion in this study (noted also by Raine, 1976) and some or all may be oligodendrocytes. Thus, although rapid CDVinduced cytolysis must be considered, the absence of acute cytolysis of other infected neurectodermal cells makes this proposition unappealing. It is further possible that oligodendrocytes are sites of defective viral infection with failure of viral assembly. Clarification of this latter possibility will require immunoelectron microscopic studies.

In contrast to oligodendrocytes, astroglial infection by $\mathrm{CDV}$ is readily and consistently demonstrated by all authors and perhaps is the primary target in white matter. It is recognized that astrocytes are important in maintaining ionic homeostasis within the neuroparenchyma (Duffy, 1983). Furthermore, they appear to contribute specifically to stability at the node of Ranvier (Raine, 1984a; Ffrench-Constant et al., 1986; Waxman, 1986). Indeed Sims et al. (1985) suggested that the perinodal astrocyte process may play a role in the development and maintenance of central myelin. Accordingly, we propose that metabolic disturbances resulting from astrocyte infection may initiate the focal oedema and myelin ballooning that marks the initial white matter injury in CDE. Myelin ballooning could well have consequences for other, still compact internodes, maintained by the same oligodendrocyte. Subtle alterations, perhaps expressed at the surface of these internodes may attract local macrophages (microglia, astroglia) which invade and demyelinate these fibres. Lampert (1978) has commented that this myelin stripping is a non-specific pattern of demyelination that always follows damage to myelin sheaths or myelin-supporting cells. The concept of bystander demyelination, whereby the release of inflammatory mediators non-specifically injures myelin sheaths would seem to have little support from this study. We commonly observed fields of 
mixed demyelinated and intact axons in immediate proximity, indicating that loss of the sheath involved a selective rather than haphazard process. Higgins et al. $(1982 \mathrm{~b})$, in their studies of demyelinating CDE, came to the same conclusion.

Wheareas microglial and astroglial cells constituted the most important source of macrophages, very rare cases of myelin phagocytosis by oligodendrocytes was encountered. This, apparently, is not a novel observation and has been recorded in lysolecithininduced demyelination (Triarhou et al., 1985) and following Wallerian degeneration in the CNS (Cook \& Wisniewski, 1973). It is probable that blood monocytes constitute an important source of phagocytes during the inflammatory phase of demyelination.

The recognition of endocytosis of myelin droplets into clathrin-coated pits on the surface of macrophages was of interest. This process also has been recorded in other primary demyelinating diseases including MS (Raine, 1984b), EAE (Epstein et al., 1983) and JHM virus encephalomyelitis (Fleury et al., 1980). It is clear that these myelin diseases of animals and man have both unique and shared features.

The fate of demyelinated axons was of considerable interest. Evidence of remyelination was found, although not in great abundance, probably in concurrence with earlier studies (McCullough et al., 1974; Higgins et al., 1982b). This may relate to the apparent replacement of mature (medium and dark) oligodendrocytes by the light variety in wellestablished white matter lesions. Light oligodendrocytes have the most active mitotic activity (Mori \& Leblond, 1970) and are probably progenitors of the dark, mature forms which contain the organelles (endoplasmic reticulum, Golgi) associated with synthetic functions. Furthermore, demyelinated axons in the loosened neuropil were invested by astroglial processes which sometimes formed spiral wrapping as others have noted in CDE (Wisniewski et al., 1972; Higgins et al., 1982b). This astroglial response may recapitulate development of the CNS wherein astroglial processes ensheath developing axons prior to their investment by cytoplasmic extensions of the oligodendroglia (Nagashima, 1979). This has also been shown in organotypic cultures of the CNS (Munoz-Garcia \& Ludwin, 1986). Whether

\section{References}

ALEU, F. P., KATZMAN, R. \& TERRY, R. D. (1963) Fine structure and electrolyte analyses of cerebral edema induced by alkyl tin intoxication. Journal of Neuropathology and Experimental Neurology 22, 403-13.

APPEL, M. J. G., SHEK, W. R. \& SUMMERS, B. A. (1982) Lymphocyte-mediated immune cytotoxicity in dogs infected with virulent canine distemper virus. Infection and Immunity 37, 592-600. in a reparative state this astroglial reaction ultimately aided or hindered remyelination is unknown, but our impressions would favour the latter interpretation. Tapered myelin sheaths and aberrantly located lateral loops which we encountered, albeit rarely, have been observed in lesions of MS (Prineas, 1975; Prineas \& Connell, 1979), and in Balo's concentric sclerosis (Moore et al., 1985), a probable variant of MS, and are taken to indicate myelin repair.

The role of the lymphoplasmacytic infiltrate which appears in the more chronic phase of CDE has not been defined. In general, evidence that immune mechanisms play a primary role in myelin injury in CDE are lacking (Cerrutii-Sola et al., 1983). In marked contrast, white matter lesions in CDE are directly associated with the presence of the virus, or its proteins, in the tissue (Vandevelde et al., 1985; Mitchell, 1987). Virus was not found in non-lesion areas (Wisniewski et al., 1972). We concur with the interpretation offered by Bollo et al. (1986) that these infiltrating cells are responding to viral rather than myelin antigens, and are attempting to clear the brain of the persistent infection. It appears that if the immune response is prompt, clearance can be effected (Appel et al., 1982) and the animal recovers. If the inflammatory reaction is delayed, the lesions expand and may change from demyelinating to necrotizing (Wisniewski et al., 1972). The capacity of astrocytes to present antigens to infiltrating T-cells may trigger this destructive process (Sun \& Wekerle, 1986), resulting in the release of lymphotoxins which produce tissue necrosis. Clarification of these events and related questions (are the astrocytes Ia positive?) should prove of interest to investigators of demyelinating diseases of the CNS.

\section{Acknowledgements}

Drs Cedric Raine and John Cummings both provided valuable assistance with interpretation of electron micrographs in this project. Expert technical assistance was provided by Sue Pearce-Kelling. We thank Amy Pellegrino for typing the manuscript and Peter Daly for excellent assistance with the photomicroscopy. Supported by the National Multiple Sclerosis Society, RG 1430.

BARON, M. \& GALLEGO, A. (1972) The relation of the microglia with the pericytes in the cat cerebral cortex. Zeitschrift für Zellforschung und mikroskopische Anatomie 128, 42-57.

BOLLO, E., ZURBRIGGEN, A., VANDEVELDE, M. \& FANKHAUSER, R. (1986) Canine distemper virus clearance in chronic inflammatory demyelination. Acta neuropathologica 72, 69-73. 
CAMPBELL, R. S. F. (1957) Encephalitis in canine distemper. British Veterinary Journal 113, 143-61.

CERRUTI-SOLA, S., KRISTENSEN, F., VANDEVELDE, M., BICHSEL, P. \& KIHM, U. (1983) Lymphocyte responsiveness to lectin and myelin antigens in canine distemper infection in relation to the development of demyelinating lesions. Journal of Neuroimmunology 4, 77-90.

COOK, R. D. \& WISNIEWSKI, H. M. (1973) The role of oligodendroglia and astroglia in Wallerian degeneration of the optic nerve. Brain Research 61, 191-206.

DUFFY, P. E. (1983) Functional implications of astrocyte metabolism. In Astrocytes: Normal, Reactive, and Neoplastic, pp. 39-44. New York: Raven Press.

EPSTEIN, L. G., PRINEAS, J. W. \& RAINE, C. S. (1983) Attachment of myelin to coated pits on macrophages in experimental allergic encephalomyelitis. Journal of the Neurological Sciences 61, 341-8.

FFRENCH-CONSTANT, C.; MILLER, R. H., KRUSE, J., SCHACHNER, M. \& RAFF, M. C. (1986) Molecular specialization of astrocyte processes at nodes of Ranvier in rat optic nerve. Journal of Cell Biology 102, 844-52.

FLEURY, H. J. A., SHEPPARD, R. D., BORNSTEIN, M. B. \& RAINE, C. S. (1980) Further ultrastructural observations of virus morphogenesis and myelin pathology in JHM virus encephalomyelitis. Neuropathology and Applied Neurobiology 6, 165-79.

GRIMLEY, P. M. \& SCHAFF, Z. (1976) Significance of tubuloreticular inclusions in the pathobiology of human diseases. In Pathobiology Annual (edited by IOACHIM, H. L.), pp. 221-57. New York: Appleton-Century-Crofts.

HIGGINS, R. J., KRAKOWKA, S. G., METZLER, A. E. \& KOESTNER, A. (1982a) Experimental canine distemper encephalomyelitis in neonatal gnotobiotic dogs. Acta neuropathologica 57, 287-95.

HIGGINS, R. J., KRAKOWKA, S. G., METZLER, A. E. \& KOEstNer, A. (1982b) Primary demyelination in experimental canine distemper virus induced encephalomyelitis in gnotobiotic dogs. Acta neuropathologica 58, $1-8$.

INNES, J. R. M. \& SAUNDERS, L. Z. (1962) (eds) Viral and rickettsial encephalomyelitides. Canine distemper. In Comparative Neuropathology, pp. 373-84. New York: Academic Press.

KITAMURA, T., MIYAKE, T. \& FUJITA, S. (1984) Genesis of resting microglia in the gray matter of mouse hippocampus. Journal of Comparative Neurology 226, 421-33.

KOESTNER, A. (1975) Animal model of human disease. American Journal of Pathology 78, 361-4.

KRISTENSSON, K. \& WISNIEWSKI, H. M. (1978) Arrest of myelination and demyelination in rabbit rętina induced by herpes simplex virus infection. Neuropathology and Applied Neurobiology 4, 71-82.

KUSAKA, H., HIRANO, A., BORNSTEIN, M. B., MOORE, G. R. W. \& RAINE, C. S. (1986) Transformation of cells of astrocyte lineage into macrophage-like cells in organotypic cultures of mouse spinal cord tissue. Journal of the Neurological Sciences 72, 77-89.

KUSAKA, H., HIRANO, A., BORNSTEIN, M. B. \& RAINE, C. S. (1985) Fine structure of astrocytic processes during serum-induced demyelination in vitro. Journal of the Neurological Sciences 69, 255-67.

LAMPERT, P. W. (1978) Autoimmune and virus-induced demyelinating diseases. American Journal of Pathology 91, 175-208.

LAMPERT, P. W., SIMS, J. K. \& KNIAZEFF, A. J. (1973) Mechanism of demyelination in JHM virus encephalomyelitis. Acta neuropathologica 24, 76-85.

LASSMANN, H., KITZ, K. \& WISNIEWSKI, H. M. (1980) Structural variability of demyelinating lesions in different models of subacute and chronic experimental allergic encephalomyelitis. Acta neuropathologica 51, 191-201.

LAVI, E., GILDEN, D. H., WROBLEWSKA, Z., RORKE, L. B. \& WEISS, S. R. (1984) Experimental demyelination produced by the A59 strain of mouse hepatitis virus. Neurology 34, 597-603.

LUDWIN, S. K. (1978) Central nervous system demyelination and remyelination in the mouse. An ultrastructural study of cuprizone toxicity. Laboratory Investigation 39, $597-612$.

MCCULLOUGH, B., KRAKOWKA, S, \& KOESTNER, A. (1974) Experimental canine distemper virus-induced demyelination. Laboratory Investigation 31, 216-22.

MITCHELL, W. J. (1987) Studies on the expression of canine distemper virus in persistent infections. PhD thesis, Cornell University.

MOORE, G. R. W., NEUMANN, P. E., SUZUKI, K., LIJTMAER, H. N., TRAUGOTT, U. \& RAINE, C. S. (1985) Balo's concentric sclerosis: new observations on lesion development. Annals of Neurology 17, 604-11.

MORI, S. \& LEBLOND, C. P. (1969) Identification of microglia in light and electron microscopy. Journal of Comparative Neurology 135, 57-80.

MORI, S. \& LEBLOND, C. P. (1970) Electron microscopic identification of three classes of oligodendrocytes and a preliminary study of their proliferative activity in the corpus callosum of young rats. Journal of Comparative Neurology 139, 1-30.

MUNOZ-GARCIA, D. \& LUDWIN, s. K. (1986) Gliogenesis in organotypic tissue culture of the spinal cord of the embryonic mouse. I. Immunocytochemical and ultrastructural studies. Journal of Neurocytology 15, 273-90.

NAGASHIMA, K. (1979) Ultrastructural study of myelinating cells and sub-pial astrocytes in developing rat spinal cord. Journal of Neurological Sciences 44, 1-12.

PRINEAS, J. (1975) Pathology of the early lesion in multiple sclerosis. Human Pathology 6, 531-54.

PRINEAS, J. W. \& CONNELL, F. (1979) Remyelination in multiple sclerosis. Annals of Neurology 5, 22-31.

RAINE, C. S. (1976) On the development of CNS lesions in natural canine distemper encephalomyelitis. Journal of the Neurological Sciences 30, 13-28.

RAINE, C. S. (1984a) On the association between perinodal astrocytic processes and the node of Ranvier in the C.N.S. Joumal of Neurocytology 13, 21-7.

RAINE, C. S. (1984b) Biology of disease. Analysis of autoimmune demyelination: its impact upon multiple sclerosis. Laboratory Investigation 50, 608-35.

RAINE, C. S., SCHEINBERG, L. \& WALTZ, J. M. (1981) Multiple sclerosis. Oligodendrocyte survival and proliferation in an active established lesion. Laboratory Investigation 45, 534-46.

RODRIGUEZ, M., LEIBOWITZ, J. L. \& LAMPERT, P. W. (1983) Persistent infection of oligodendrocytes in 
Theiler's virus-induced encephalomyelitis. Annals of Neurology 13, 426-33.

SCHELPER, R. L. \& ADRIAN, E. K. (1986) Monocytes become macrophages; they do not become microglia: a light and electron microscopic autoradiographic study using 125-Iododeoxyuridine. Journal of Neuropathology and Experimental Neurology 45, 1-19.

SHEAHAN, B. J., GATES, M. C., CAFFREY, J. F. \& ATKINS, G. J. (1983) Oligodendrocyte infection and demyelination produced in mice by the M9 mutant of Semliki Forest virus. Acta neuropathologica 60, 257-65.

SIMS, T. J., WAXMAN, S. G., BLACK, J. A. \& GILMORE, s. A. (1985) Perinodal astrocytic processes a nodes of Ranvier in developing normal and glial cell deficient rat spinal cord. Brain Research 337, 321-31.

SMITH, M. E., SOMERA, F. P. \& ENG, L. F. (1983) Immunocytochemical staining for glial fibrillary acidic protein and the metabolism of cytoskeletal proteins in experimental allergic encephalomyelitis. Brain Research 264, 241-53.

SUMMERS, B. A., GREISEN, H. A. \& APPEL, M. J. G. (1978) Possible initiation of viral encephalomyelitis in dogs by migrating lymphocytes infected with distemper virus. Lancet ii, 187-9.

SUMMERS, B. A., GREISEN, H. A. \& APPEL, M. J. G. (1979) Early events in canine distemper demyelinating encephalomyelitis. Acta neuropathologica 46, 1-10.

SUMMERS, B. A., GREISEN, H. A. \& APPEL, M. J. G. (1984) Canine distemper and experimental allergic encephalomyelitis in the dog: comparative patterns of demyelination. Journal of Comparative Pathology 94, 575-89.
SUN, D. \& WEKERLE, H. (1986) Ia-restricted encephalitogenic T lymphocytes mediating EAE lyse autoantigenpresenting astrocytes. Nature 320, 70-2.

TRIARHOU, L. C., DEL CERRO, M. \& HERNDON, R. M. (1985) Ultrastructural evidence for phagocytosis by oligodendroglia. Neuroscience Letters 53, 185-9.

VANDEVELDE, M., BICHSEL, P., CERRUTI-SOLA, S., STECK, A., KRISTENSEN, F. \& HIGGINS, R. J. (1983) Glial proteins in canine distemper virus-induced demyelination. Acta neuropathologica 59, 269-76.

VANDEVELDE, M., HIGGINS, R. J., KRISTENSEN, B., KRISTENSEN, F., STECK, A. J. \& KIHM, U. (1982) Demyelination in experimental canine distemper virus infection: immunological, pathologic, and immunohistological studies. Acta neuropathologica 56, 285-93.

VANDEVELDE, M., ZURBRIGGEN, A., HIGGINS, R. J. \& PALMER, D. (1985). Spread and distribution of viral antigen in nervous canine distemper. Acta neuropathologica $67,211-18$.

WAKSMAN, B. H. (1981) Current trends in multiple sclerosis research. Immunology Today 2, 1-7.

WAXMAN, S. G. (1986) The astrocyte as a component of the node of Ranvier. Trends in Neuroscience: 9, 250-3.

WISNIEWSKI, H., RAINE, C. S. \& KAY, W. J. (1972) Observation on viral demyelinating encephalomyelitis. Laboratory Investigation 26, 589-99.

YAJIMA, K. \& SUZUKI, K. (1979) Ultrastructural changes of oligodendroglia and myelin sheaths induced by ethidium bromide. Neuropathology and Applied Neurobiology 5, $49-62$. 